\title{
OS CATADORES DE RESÍDUOS E A RESPONSABILIDADE SOCIOAMBIENTAL: A PERCEPÇÃO SOBRE SEU LUGAR SOCIAL
}

\author{
Fernando Filardi \\ Doutor em Administração pela Universidade de São Paulo - USP \\ Professor e pesquisador da Universidade do Grande Rio - Unigranrio \\ fernandofilardi@gmail.com
}

\author{
Elisabete Stradiotto Siqueira \\ Doutora em Ciências Sociais pela Pontifícia Universidade Católica de São Paulo - PUC/SP \\ Professora da Universidade Federal do Semi-Árido - UFERSA \\ betebop@uol.com.br
}

Erlaine Binotto

Doutora em Agronegócios pela Universidade Federal do Rio Grande do Sul - UFRGS

Professora da Universidade Federal da Grande Dourados - UFGD

e-binotto@uol.com.br

\begin{abstract}
RESUMO
A preocupação da sociedade com ações voltadas para uma melhor relação com o meio ambiente têm se intensificado nas últimas décadas. Uma das dimensões dessa questão está relacionada com o destino dos resíduos sólidos e o processo de reciclagem. Um novo ator social emergiu desse cenário, conhecido como "catadores de lixo", cuja situação social insere-se na dubiedade da dimensão ambiental, pois, ao mesmo tempo em que, o lixo lhes proporciona trabalho informal, por outro lado as condições de vida e salubridade nem sempre correspondem à dignidade social. $\mathrm{O}$ texto analisa a percepção desses atores com relação a esta contradição, no sentido de apurar que nível de compreensão eles possuem sobre as possibilidades e limitações que este tipo de inserção social tem possibilitado. Trata-se de um estudo exploratório, que utilizou-se como meio de investigação a pesquisa de campo. Foram entrevistados 21 "catadores" da região da AMURES (Associação dos Municípios da Região Serrana de Santa Catarina), que coletam na rua e os resultados indicam que a contraditoriedade desse vínculo social nem sempre é percebida de forma clara pelos envolvidos. Alguns relatam sentir orgulho de sua atividade, porém esse processo gera uma dubiedade, pois se de um lado ameniza os processos de exclusão social, de outro mascara a ineficiência do sistema produtivo que não é capaz de lidar com o ciclo que relaciona natureza - matéria-prima - produto - consumo - descarte. A pesquisa mostrou que existe um grande distanciamento da ação dos catadores com as organizações.
\end{abstract}

Palavras-chave: Catadores de lixo; Questão social ambiental, Reciclagem.

\section{SCAVENGERS AND ENVIRONMENTAL AND SOCIAL RESPONSIBILITY: PERCEPTIONS OF THEIR SOCIAL PLACE}

\begin{abstract}
Society's concern regarding actions for a better relationship with the environment has intensified in recent decades. One dimension of this issue is related to the fate of solid waste and recycling processes. A new social actor emerged from this scenario, known as "garbage collectors", whose social situation is part of the ambiguity of the environmental dimension, because at the same time that the garbage provides them with informal work, on the other hand the living conditions and health not always correspond to social dignity. This paper examines the perceptions of these actors with respect to this contradiction in order to determine what level of understanding they have about the possibilities and limitations that this type of social integration has made possible. This is an exploratory study which was used as a means of investigation in field research. We interviewed 21 "garbage collectors" of the AMURES region (Association of Municipalities in the Mountainous Region of Santa Catarina), which collect in the street and the results indicate that the contradiction of the social bond is not always perceived clearly by those involved. Some report feeling proud of their activity, but this process generates an ambiguity because if one side softens the processes of social exclusion, the other masks the inefficiency of the production system that is not capable of dealing with the cycle that relates nature, raw material, product, consumption, and disposal. The research shows that there is a large distance from the action of garbage collectors to the organizations.
\end{abstract}

Keywords: Garbage Collectors; Social and Environmental Issues; Recycling. 


\section{INTRODUÇÃO}

O problema dos resíduos sólidos na sociedade moderna foi agravado com o aceleramento do processo industrial que agregou às matérias-primas, retiradas da natureza, propriedades que a tornaram um elemento estranho ao sistema natural.

Segundo Capra (1996) o ecossistema foi concebido de forma a não produzir resíduos, uma vez que se constitui em uma cadeia perfeita em que os resíduos de uma espécie são alimentos de outra. Nesse contexto, a noção de reciclagem faz parte de um ciclo natural da vida.

A sociedade de consumo, que caracterizou principalmente a segunda metade do século XX, agregou a percepção humana uma visão equivocada do processo natural. Korten (1990), para explicar tal perspectiva, usa a metáfora do astronauta e o cowboy, enquanto o último tem a visão do horizonte como algo sem limites, o astronauta somente sobrevive através do cálculo preciso dos recursos necessários e o quanto esses produzirão de descarte. Este equilíbrio é fundamental para a sustentabilidade de sua jornada.

Cabe considerar as desigualdades sociais produzidas pela inexistente distribuição da renda, causada, principalmente pela produtividade tecnológica, desenham um cenário, em curto prazo, absolutamente preocupante, uma vez que se assiste ao esgotamento das possibilidades de estabelecer um ciclo de produção de soma zero. Senge (2000) sugere que o processo industrial deveria ser responsável por todo o ciclo produtivo, envolvendo desde a retirada da matéria-prima até o destino final do resíduo de seus produtos e também suas embalagens, tomando como referência a forma como a natureza lida com seus resíduos como comentado por Capra (1996).

O desperdício, a cultura descartável que em um olhar simplista conduziria a comodidade e o conforto, tem trazido efeitos degradantes levando o planeta aos limites da insustentabilidade.

É nesse contexto de complexidade econômica, cultural, ambiental e social que localizamos a temática dos resíduos sólidos produzidos pela população em geral, que por sua vez está inserido na trama de todo o processo industrial.

As relações do homem com a natureza são tão antigas quanto a própria existência da humanidade. As características dessas relações, entretanto, se alteraram significativamente com o decorrer do tempo, condicionadas pelo processo de desenvolvimento a que o homem sempre esteve sujeito.

O espaço constituído é ao mesmo tempo um fato físico e um fato social, em seus atributos de propriedade, valor e símbolo. Cumpre acentuar que o espaço como manifestação social, ou seja, como forma de objetividade das relações que se estabelecem entre os homens, constitui uma das múltiplas determinações que operam no interior da totalidade social, desempenhando o papel de seu reprodutor material. Em compensação, como elemento físico, ele condiciona as ações sociais, impondo restrições à sua realização (CASE, 2000).

Tomamos a concepção do urbano enquanto uma possibilidade de percepção dos espaços da cidade, ou seja, como linguagem em contínuo movimento de construção e reconstrução, que traz em si, singularidades e contradições e que, portanto, não suporta a aceitação de uma idéia de uso única e exclusivamente pensada a dimensão do tratamento dos resíduos sólidos assume caráter contraditório.

Para Ferrara (2000) o espaço urbano consiste no resultado da atividade do conjunto, que dinamiza suas estruturas, enriquece a cidade de significados, isto é, uma prática cultural que caracteriza certa compreensão da cidade que se apóia no uso urbano. A cidade está permeada de signos, linguagens - ruas, praças, sinais de trânsito, monumentos, faróis - que estão em constante remodelação. A cidade é formada por signos, linguagem estabelecida pelos usuários (o uso e sua fala, sua linguagem, e tem relação com o repertório do usuário, com sua forma de ser, pensar, agir, conseguintes da sua educação, cultura e contexto social em que está inserido).

Tal compreensão do urbano, parte do contexto social, psicológico, antropológico, filosófico, comunicacional, enfim, humano, que deve interagir com as pessoas e com a sociedade que o abriga. 
Os usos não são previsíveis porque são leituras da cidade e não se amoldam às normas, isto é, cada pessoa usará um determinado espaço de forma única, assim como não se podem prever futuros usos, não existe linearidade lógica. Por essa razão o projeto oficial agride o usuário, por não levar em conta suas expectativas, desejos e necessidades. Por esta razão, alguns projetos nunca foram ou serão usados da forma para a qual foram planejados (FERRARA, 2000).

Desta forma, o urbano deveria expressar a identidade de seus usuários que inscrevem ali sua história e traços de sua memória, e desta forma o passado não foi, mas se inscreve permanentemente na atribuição de sentidos do que ele é e nos convida a reassimilá-la.

É neste espaço que estão gravados o que o usuário escreveu, onde está escrito a história do repertório coletivo e não se esgota com a simples conservação de seus ícones. Quando se usa o espaço, quando se cria novas formas de uso, está-se construindo na cidade a história do urbano, e essa construção não interessa só porque ainda é, mas porque o que já passou ainda está enraizado no presente, que se percebe no mínimo através dos signos deixados pela ausência das edificações simbólicas (FERRARA, 2000). Então, espaço urbano é a produção cultural de linguagem que rompe o espaço projetado para transformá-lo através do uso.

Pesquisar como a população cria esses mecanismos de intervenção e aplica-os na transformação contínua da cidade contribui para a elaboração de abordagens científicas que não se prendam a um ponto de vista fragmentário de conhecimento. Uma vez que, hoje se torna cada vez mais importante a consciência de preservação, participação e valorização urbana como forma de buscar melhoria da qualidade de vida das pessoas que moram nas cidades. Nesta perspectiva, buscase desenvolver novas abordagens caracterizadas por interfaces com outras ciências e que a complexidade criada nesta abordagem favoreça o conhecimento produzido.

É nesse contexto dos processos de apropriação da cidade que se propõe analisar a situação social dos catadores de lixo, no sentido de perceber como eles se inserem na dubiedade da dimensão ambiental, pois ao mesmo tempo em que o lixo lhes proporciona trabalho informal, por outro, as condições de vida e salubridade nem sempre correspondem à dignidade social.

\section{REFERENCIAL TEÓRICO}

\subsection{Um cenário sobre a produção de resíduos sólidos e a reciclagem}

Do ponto de vista histórico o lixo passou a ser considerado algo que deveria ser removido das cidades por volta de 1779, mas ainda assim era primordialmente orgânico. O trabalho do lixeiro surge na França no século XIX e só em 1846 mereceu orçamento e cuidados próprios (CARMO, OLIVEIRA e MIGUELES, 2004)

A Constituição Federal designa para as municipalidades a responsabilidade pelo gerenciamento e destinação do lixo domiciliar (SOARES-BAPTISTA, 2003). Segundo Abreu (2001) 25 a 30\% do lixo é reciclável, 65 a $70 \%$ são de materiais biodegradáveis e somente $5 \%$ poderiam ser caracterizados como rejeitos.

Esses dados são confirmados pelo IBGE (2007) quando afirma que 30\% do lixo pode ser reciclado, e $60 \%$ é material orgânico, passível de compostagem. Magera (2003) salienta que a proporção de lixo reciclável aumenta para a população de maior renda.

Esses números são resultados de uma política, desenvolvida durante o século $\mathrm{XX}$, marcada "pela ausência de uma política adequada para o setor, a falta e a pulverização de recursos, a centralização das ações, a ausência de controle social, a susceptibilidade do aparato estatal aos interesses de grupos sociais." Contudo, esse perfil vem sendo modificado, diante de pressões relacionadas ao controle social, meio ambiente saudável, desenvolvimento ecológico e igualdade social (MARCHI, 2006, p. 1).

Esses dados indicam que a problemática dos resíduos sólidos está concentrada no aspecto cultural, que durante o desenvolvimento do processo industrial não construiu uma distinção entre um amplo espectro que denominamos genericamente de LIXO. 
Os problemas decorrentes do esgotamento dos espaços para aterros sanitários e suas conseqüências para a dimensão ambiental, como a contaminação de lençóis freáticos, periculosidade de enfermidades, entre outras, contribuiu para um processo de uma reflexão mais profunda do significado do lixo. Segundo Caderoni (1997) a reciclagem pode produzir economias significativas para toda a sociedade, e quando não realizada redunda em desperdício.

O significado social atribuído, historicamente ao lixo, como algo que se deve manter distância, dificulta uma mudança cultural que envolva a população em uma ação conjunta que reverta à atual lógica de descarte.

É nesse cenário que os catadores surgem como atores sociais, uma vez que, dada suas condições de exclusão, aceitam o contato com o lixo como forma de sobrevivência e, posteriormente, outros atores se inserem nesse cenário ao vislumbrarem na atividade uma fonte de renda complementar.

Tabela 1: Destino dos resíduos sólidos urbanos

\begin{tabular}{|c|c|c|c|}
\hline \multicolumn{3}{|c|}{ DESTINO DOS RESÍDUOS SÓLIDOS URBANOS } \\
\hline País & $\begin{array}{c}\text { Aterros } \\
\text { e/ou lixões }\end{array}$ & $\begin{array}{c}\text { Incineração com } \\
\text { recuperação de energia }\end{array}$ & $\begin{array}{c}\text { Compostagem } \\
\text { + Reciclagem }\end{array}$ \\
\hline Brasi*1 & $89 \%$ & ------ & $11 \%$ \\
\hline República Tcheca*2 & $76 \%$ & $14 \%$ & $10 \%$ \\
\hline Espanha*2 & $62 \%$ & $6 \%$ & $32 \%$ \\
\hline França*2 & $41 \%$ & $32 \%$ & $27 \%$ \\
\hline Itália*2 & $58 \%$ & $8 \%$ & $34 \%$ \\
\hline Portugal*2 & $73 \%$ & $20 \%$ & $7 \%$ \\
\hline Reino Unido*2 & $79 \%$ & $7 \%$ & $14 \%$ \\
\hline Hungria*2 & $92 \%$ & $6 \%$ & $2 \%$ \\
\hline Suécia*3 & $9,7 \%$ & $46,7 \%$ & $3,6 \%$ \\
\hline Estados Unidos*4 & $54,4 \%$ & $13,6 \%$ & $32 \%$ \\
\hline Argentina*5 & $95 \%$ & ------- & $5 \%$ \\
\hline Colômbia*1 & $95 \%$ & ------- & $5 \%$ \\
\hline Tailândia*6 & $30 \%$ (só aterro) & $54 \%$ (inclui lixões) & \\
\hline
\end{tabular}

Fonte: *1 Cempre (2005), *2 Eurostat (2005), *3 Warmer Bulletin (set/06), *4 US Environmental Protection Agency (2005), *5 Coordenação Ecológica Área Metropolitana Sociedade do Estado/Ceamse (2005);

*6 Thailand Institute of Packaging Management for Sustainable Environment/TIPMSE (2004)

Segundo o CEMPRE - Compromisso Empresarial para Reciclagem (2005) o índice nacional de $11 \%$, de reciclagem e compostagem de resíduos sólidos urbanos, está acima da República Tcheca, Portugal, Argentina, Colômbia e Hungria e chega perto do Reino Unido. Em 2005, o volume reciclado foi de 5,7 milhões de toneladas, 760 mil toneladas a mais do que em 2004. Nesse total, as participações de alumínio, embalagem longa vida e papel cresceram, enquanto vidro e aços tiveram pequenas quedas. Verifica-se que ainda há um trajeto muito longo a ser percorrido pelo Brasil nos processos de reciclagem.

O problema é mais grave se considerarmos a capacidade que os municípios brasileiros têm para a coleta de lixo. De acordo com Perin (2003), apoiado em dados do IBGE, dos 5.475 municípios brasileiros pesquisados, apenas um terço deles (1.814 municípios) apresentam coleta convencional em $100 \%$ da cidade, ou seja, muito distante de condições mínimas necessárias.

Marchi (2006) afirma que dos 2,9 milhões de resíduos industriais gerados por ano somente 600 mil toneladas são tratadas. Segundo o IBGE (2002), apenas $2 \%$ do lixo produzido no país passam por processo de seleção antes de chegar ao seu destino final.

Vale salientar que a coleta do lixo é apenas parte do processo, uma vez que a ausência de tratamento esgota os espaços de despejo prejudicando as localidades em que estão implantados. Marchi (2006) alerta que $60 \%$ das cidades de pequeno e médio porte do país não desenvolvem nenhum tipo de tratamento para os resíduos coletados. Salienta também que 62,2\% dos municípios 
pesquisados não têm conhecimento do local para onde vai o lixo e 71,6\% não recordam de nenhuma campanha educativa sobre a questão.

As campanhas de conscientização quanto ao processo de reciclagem têm sido um dos instrumentos de reversão desse problema, contudo, não ocorre paralelamente uma conscientização da população quanto ao destino do lixo, dificultando o controle social da questão.

A reversão desse panorama deveria ter como parceiro fundamental a população, que ao exercer controle social ampliaria a discussão no campo sócio ambiental e ainda poderia contribuir na construção de alternativas para minimização do problema.

\subsection{Os catadores e a cultura do lixo}

A coleta e destinação do lixo constituem-se em redes formais, semi-informais e informais no contexto de uma mesma cadeia, uma vez que envolvem catadores individuais, organizações formais, associações independentes, o setor público e empresas privadas. Os catadores funcionam como uma disfunção dos pólos público e privado, uma vez que é a deficiência desses setores no tratamento da questão que permite o surgimento dessa atividade (SOARES-BAPTISTA, 2003).

De acordo com a BRACELPA - Associação Brasileira e Celulose e Papel (2007) esse tipo de atividade é muito antiga e está concentrada nos moradores de rua e mendigos que encontravam dessa forma meios de complementar suas estratégias de sobrevivência.

A reestruturação produtiva, ocorrida principalmente após a década de 1960 gera uma reorganização no mercado de trabalho que relega uma parcela significativa da população ao desligamento do trabalho formal vinculado a atividade empresarial obrigando-os a construírem outras formas de sobrevivência. Segundo Antunes (1995) e Rifkin (1995) não se trata de desemprego, mas fundamentalmente de funções que desapareceram da estrutura produtiva e excluíram definitivamente um tipo de mão de obra incapaz de migrar para outro tipo de profissão até então conhecida.

Dessa forma aliam-se aos mendigos e moradores de rua aqueles trabalhadores expulsos do mercado clássico de trabalho.

Os catadores, no Brasil, são considerados como os maiores responsáveis pelos altos índices de reciclagem de alguns materiais - latas de alumínio (73\%) e papelão (71\%) — colocando o país em posição de destaque no cenário mundial, sendo que as cooperativas vêm se transformando em empreendimentos cada vez mais rentáveis (CEMPRE, 2005).

Esse agente social, criado em tal contexto, ocupa a contraditoriedade do sistema social que os produziu, pois ao mesmo tempo em que o trabalho de catação lhes possibilita um nível de renda, diminuindo sua dependência de ações caritativas, por outro lado sofrem o preconceito da população dada as condições precárias que envolvem seu trabalho.

O cenário dessa atividade não se desenvolveu sem conflitos, algumas prefeituras, como a de São Paulo na década de 1980 adotaram medidas repressivas da atividade, por considerar que essa era responsabilidade exclusiva do Estado (SOARES-BAPTISTA, 2003).

Segundo o autor, como resposta a repressão inicia-se os primeiros movimentos de organização que reivindicavam o direito ao trabalho e a constituição de uma identidade profissional.

Os catadores passam a fazer parte dos novos movimentos sociais (JACOBI, 1991) e iniciam a demarcação de um campo contraditório de atuação.

Em 2001, ocorre em Brasília um grande encontro nacional com a finalidade de recenseamento e troca de experiências que tem como principal conquista o reconhecimento, em 2002, da atividade na Classificação Brasileira de Ocupações (SOARES-BAPTISTA, 2003).

Contudo, os autores reforçam que esse processo organizativo enfrenta dificuldades, os catadores resistem em utilizar equipamentos que minimizem os riscos de sua atuação e tem dificuldades de superar a cultura do trabalho individual. Além disso, a fidelidade à cooperativa nem sempre é respeitada, sendo que alguns catadores negociam o material coletado pelo melhor preço, fragilizando a experiência associativa. 
Carmo (2005), referindo-se a um estudo de Putnam (2002), sugere que tais dificuldades poderiam estar vinculadas a dificuldade de construção de um capital social que poderia ser classificado em: ponte (entre redes), união (no interior do grupo) e conexão (pessoas de posição social de destaque) que facilitasse as atividades solidárias nesse campo.

Carmo, Oliveira e Migueles (2004) acrescentam que essas dificuldades também estariam vinculadas aos aspectos simbólicos atribuídos a atividade. Considerando que a atividade de catar lixo é uma degradante, restrita a pessoas de baixa renda, produz dificuldade de construção de uma identidade coletiva capaz de facilitar os processos de organização e também de uma identidade profissional. Segundo os autores a catação não seria vista como um projeto de vida, mas uma situação transitória. A reversão desse quadro só poderia ocorrer através da construção de um capital social capaz de elevar a auto-estima desses trabalhadores. Nesse sentido, a vertente ambiental assume importância marcante para a inclusão desse agente de forma positiva no contexto social.

Existe nesse cenário uma série de lógicas que estruturam o trabalho, são elas: associação, cooperação, competição, hierarquia e reputação.

Desde que o lixo começa a ser compreendido como uma mercadoria e, portanto, passível de valor, se estabelece um contexto de competição, pois pessoas que ocupam posições profissionais clássicas, como porteiros, domésticas, faxineiras de empresas, montadores e entregadores de móveis e eletrodomésticos, constituem um mercado concorrencial, uma vez que tem acesso direto ao lixo que não está marcado por uma semântica negativa, uma vez que seu recolhimento não depende de um trabalho de arqueologia em containers, sacos de lixo e outros tipos de depósito.

De outro lado, esses novos concorrentes, desfrutam da confiabilidade daqueles que disponibilizam tal material, ocupando uma posição preferencial.

Nesse sentido restam duas alternativas. De um lado, a constituição de uma organização capaz de construir uma reputação que lhe possibilite o acesso a clientes estáveis, ou por outro lado, o trabalho isolado que sobrevive da garimpagem dos depósitos de lixo. Nesse sentido, segundo Carmo (2005) a semântica negativa do lixo é um fator que preserva esse elo da cadeia produtiva, qual seja, aquele resíduo que está misturado com matéria orgânica e outros, que por sua vez oferecem maior periculosidade para a atividade.

Pode-se afirmar que a valorização do lixo como mercadoria relegou esse mercado de trabalho, constituído pelos catadores individuais, um degrau abaixo da cadeia produtiva.

A essa situação Carmo (2005, p. 10) denomina "pulo do gato" que se refere "à expertise que o catador adquire ao longo de sua trajetória e que propiciaria uma habilidade superior aos zeladores dos edifícios atualmente encarregados de separar material aproveitável antes de o resíduo ser descartado", portanto, contraditoriamente é a afinidade com semântica negativa do lixo que lhe permite uma tentativa de superar as dificuldades da concorrência.

Por incrível que possa parecer, esse tipo de trabalho, exige por parte do catador um processo de gestão de conhecimento, sobre os conhecimentos tácitos que envolvem a atividade.

Outro problema enfrentado pelos catadores diz respeito à informalidade das relações, pois como trata-se de uma relação de confiança com quem disponibiliza o resíduo em alguns casos ele pode perder o "ponto" para outro catador, prejudicando sua atividade, questão que poderíamos atribuir aos custos de transação.

Portanto, quando se aborda esse mercado de trabalho, não se está isento de discutir a questão do desemprego, uma vez que a reestruturação valorativa atribuída aos resíduos sólidos recicláveis coloca em risco a manutenção desse trabalho (CARMO, 2005).

Carmo, Oliveira e Migueles (2004) identificaram em sua pesquisa alguns tipos de catadores: catador de usina ou aterro sanitário (selecionam o lixo da coleta urbana), catador de rua ou predatório de rua (antecipam a coleta e espalham o que não interessa), catador cooperado ou não (são mais disciplinados) e carroceiros (além de atividades de frete recolhem recicláveis).

Diante dos fatores elencados, os autores apontam as dificuldades desses sujeitos e de sua auto-estima sem que se construa para o lixo um significado social positivo, tais como: o meio 
ambiente, no interior da categoria de catadores, estejam eles organizados ou não, mas principalmente na sociedade, que não compreende que essa atividade ameniza um desvio da forma como esta encara o consumo e suas conseqüências. Trata-se de responsabilizar aqueles que são responsáveis pela produção dos resíduos, organizações e sociedade, a resignificar o valor desse trabalho que a população de forma geral transfere para esses agentes sociais.

\subsection{As formas associativas e a construção de redes de solidariedade}

Um dos problemas centrais da sobrevivência dos agentes envolvidos com a catação de lixo está relacionado ao seu isolamento que o relega a uma posição desfavorável na cadeia produtiva, uma vez que sua atividade tem pouco valor agregado.

Segundo Carmo (2005), o catador de lixo é o principal responsável pelo início do processo de reaproveitamento e sua transformação em mercadoria, seguido dos donos de caminhões, sucateiros, atravessadores e finalmente as indústrias que venderão o produto para aqueles que novamente devolverão o processo para a sociedade.

O processo de agregar valor em cada elo da cadeia está relacionado ao beneficiamento (pureza dos resíduos) ou o acúmulo (CARMO, 2005). Esse ciclo, que se desenvolveu de forma mais significativa na segunda metade do século XX gerou interesse econômico atribuindo ao lixo à categoria de produto. Contudo, de acordo com a autora, essa resignificação não eliminou a semântica negativa do lixo.

A reversão do quadro de exclusão, a que estão submetidos esses trabalhadores, carece de um encurtamento dessa cadeia, possibilitando que as atividades de catar lixo sejam incluídas outras capazes de minimizar os efeitos negativos desse tipo de atuação, como também possibilitar outros ganhos capazes de diminuir a periculosidade a que estão submetidos diariamente e também uma melhoria da auto-imagem desses agentes atualmente alvos de escárnio e repulsa por parte da população.

Como foi dito anteriormente, a atividade de catar lixo só é possível porque os elos do processo de industrialização são falhos, ou seja, não se responsabilizam pelo retorno do rejeito da sua produção (seja em forma de embalagem, descarte do produto após o uso). Considerando que uma ação dessa natureza depende de medidas em longo prazo, tanto por parte das empresas como da cultura da sociedade em re-destinar esse tipo de descarte para o local responsável pela sua destinação, algumas medidas paliativas têm sido gestadas.

A principal delas são as cooperativas de catadores que reúnem trabalhadores dessa área com o intuito de melhorar o preço dos produtos através da quantidade para comercialização e também algum beneficiamento inicial capaz de agregar maior valor.

Cardoso e Carvalho Neto (2004) relatam a experiência da ASMARE - Associação dos Catadores de Papel, Papelão e Materiais Recicláveis de Belo Horizonte. Segundo os autores, essa cooperativa incluiu em sua estratégia de atuação a formação de uma rede que inclui empresas privadas, organizações públicas e associações do terceiro setor a fim de construir sua sustentabilidade, visto que essa é uma das principais dificuldades desse tipo de organização.

Os mesmos autores afirmam que a construção dessa estrutura possibilitou a aglutinação de capital social que alavancou as atividades tanto do ponto de vista de ações sociais complementares aos associados como alfabetização, restaurante, espaço cultural, como também o investimento em equipamentos que visaram diminuir os riscos dos catadores em suas atividades diárias, através de processos de mecanização. Tal processo também permitiu a implantação de elos que encurtaram a cadeia produtiva agregando maior valor ao produto ao eliminar alguns intermediários (CARDOSO; CARVALHO NETO, 2004).

Por outro lado, essa iniciativa aproximou a problemática dos resíduos das empresas, que em última instância são os principais responsáveis por sua produção, que de alguma forma, através de ações de responsabilidade social incluíram em seu plano estratégico esse tipo de preocupação.

Revista de Gestão Social e Ambiental - RGSA, São Paulo, v. 5, n. 3, p. 17-35, set./dez. 2011. 
Nesse sentido os eixos que conduzem esse tipo de lógica estrutural são: parceria, redes, responsabilidade social e condução gerencial.

O capital social construído nessa iniciativa poderá, em longo prazo, incentivar as empresas privadas envolvidas a repensar sua lógica de produção no que diz respeito a suas ações residuais.

Tal perspectiva aproxima-se daquilo que Dowbor (1999) denomina de gestão social que traz para esse campo organizacional a questão da complexidade, de uma visão não fragmentada. Trabalha com a interdisciplinaridade, com o dinamismo das cidades e suas sociedades.

A dimensão social refere-se à inclusão do termo cidadão na tomada de decisões. Envolvem tanto ações políticas, que necessariamente inclui a participação do Estado, como ações privadas, através de parcerias de qualquer natureza, que visem os direitos e necessidades do cidadão através de condutas para o desenvolvimento da justiça social. Trata-se de observar a forma como se dão as inter-relações que tais práticas estabelecem com a sociedade.

No Brasil, o processo de urbanização foi extremamente rápido e desenfreado e não foi acompanhado pelo atendimento das necessidades da população por esses bens públicos. Constata-se que se atingiu um desequilíbrio dramático entre as dimensões produtivas e a dimensão social.

Busca-se inteligentemente, entre os diversos atores econômicos e sociais interessados, as soluções negociadas que permitirão maximizar o interesse social, econômico e ambiental. Significa incorporar nas decisões empresariais, ministeriais, comunitárias ou individuais, as diversas dimensões e os diversos impactos que cada ação pode ter em termos de qualidade de vida. Em termos práticos, tem-se que aprender a construir uma sociedade economicamente viável, socialmente justa, e ambientalmente sustentável.

\section{PROCEDIMENTOS METODOLÓGICOS}

A pesquisa caracterizou-se por um estudo descritivo e exploratório de caráter qualitativo, complementado por dados quantitativos (VERGARA, 2004). Utilizou-se como meio de investigação a pesquisa de campo. Foram entrevistados 21 "catadores de lixo", dispersos na região da AMURES (Associação dos Municípios da Região Serrana de Santa Catarina), que desenvolvem sua atividade colhendo resíduos sólidos das residências. A AMURES constitui-se de 18 municípios (Anita Garibaldi, Bocaina do Sul, Bom Jardim da Serra, Bom Retiro, Campo Belo do Sul, Capão Alto, Cerro Negro, Correia Pinto, Lages, Otacílio Costa, Painel, Palmeira, Ponte Alta, Rio Rufino, São Joaquim, São José do Cerrito, Urubici e Urupema) que ocupam uma área aproximada de 16 mil $\mathrm{km}^{2}$, com uma população aproximada de 297.700 habitantes. Para este trabalho, os catadores foram identificados como aqueles que coletam lixo na rua ou predatório de rua (antecipam a coleta e espalham o que não interessa) e carroceiros (além de atividades de frete recolhem recicláveis), classificados por Carmo, Oliveira e Migueles (2004).

$\mathrm{O}$ universo da pesquisa não pôde ser definido porque não há dados cadastrados com os sujeitos que exercem esse tipo de trabalhado. O critério utilizado para a seleção dos participantes da pesquisa considerou a acessibilidade e a disponibilidade para a participação, o que se configurou em uma restrição de delimitação da pesquisa, pois os catadores não possuem endereço nem telefone. A definição dos sujeitos da pesquisa ocorreu pelo critério exaustão, ou seja, quando as respostas começaram a repetir um padrão sem novas informações foi encerrada a coleta de dados.

Dentre os pesquisados, há predominância de respondentes habitantes da cidade de Lages, o que se justifica pela acessibilidade a esses sujeitos e pela cidade ser a maior na AMURES.

No instrumento de coleta de dados utilizou-se um roteiro de entrevista estruturado, constando de perguntas objetivas e abertas que foi aplicado, para alguns, nas residências dos trabalhadores, sempre que possível, e para outros nas ruas das cidades enquanto desenvolviam suas atividades. As categorias de análise constituíram-se de: perfil do catador, remuneração da atividade dos catadores, relação com a sociedade e relação com as empresas.

$\mathrm{Na}$ fase de tratamento dos dados foi utilizado o software SPSS, onde foi desenvolvida uma análise estatística com utilização de diversos tipos de gráficos priorizando a as ferramentas 
quantitativas. No entanto, os resultados obtidos desta pesquisa foram analisados não apenas de forma quantitativa, por se entender que a riqueza da pesquisa se dá na análise mais aprofundada do discurso e das informações prestadas pelos entrevistados, tendo sido complementadas, sempre que possível, com base na análise qualitativa.

\section{APRESENTAÇÃO DOS RESULTADOS DA PESQUISA}

Antes de apresentar a análise dos resultados da pesquisa é essencial destacar a importância do catador. Para tal, foi elaborada a figura 1, que esboça a cadeia produtiva da atividade buscando identificar os nexos que agregam valor e como o setor industrial se beneficia com esse processo.

Figura 1: Cadeia produtiva dos catadores

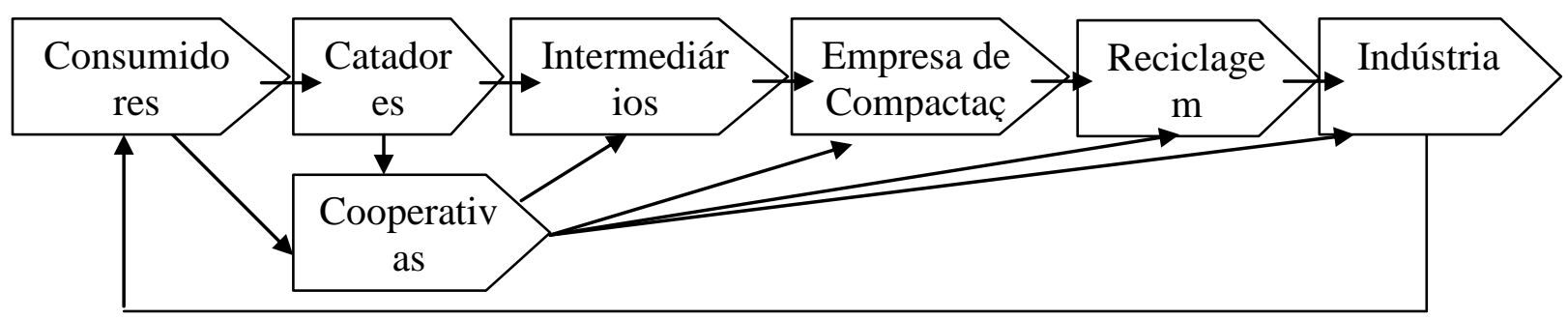

Fonte: Elaborado pelos autores (2007)

Assim, tem-se que os consumidores de bens podem ser caracterizados como pessoas físicas e jurídicas que acumulam lixo. Os catadores ou cooperativas recolhem e encaminham para intermediários ou empresas de captação. Os catadores podem vender para cooperativas ou intermediários sendo que as cooperativas vendem para intermediários, empresas de captação ou compactam e enviam direto para reciclagem ou reciclam e enviam para indústria. No que tange ao catador, as indústrias, ao tentarem se eximir da responsabilidade sobre os resíduos que produzem, enxergam este personagem como um amortecedor de impacto uma vez que estes contribuem na redução dos resíduos que essas produzem em embalagens e demais componentes dos seus produtos.

Seguindo o roteiro de entrevista estruturada foram explorados quatro aspectos sobre o tema: o perfil do catador, sua remuneração, sua relação com a sociedade e sua relação com as empresas. Temas estes que serão trabalhados nos tópicos que seguem. Ainda assim, vale ressaltar que os resultados obtidos na pesquisa serão analisados não apenas de forma quantitativa, tendo sido complementada as informações, sempre que possível, com base na análise qualitativa.

\subsection{Perfil do Catador}

No que diz respeito ao perfil desses sujeitos, um resultado que de certa forma surpreendeu, foi de que apenas $19,05 \%$ dos catadores eram pessoas que sempre estiveram desempregadas. Os demais $80,95 \%$ já tinham tido alguma experiência no mercado, experiências estas divididas entre comércio com apenas $4,76 \%$ e indústria e serviços, com $38,1 \%$ cada. Vale salientar que os setores que mais expulsaram trabalhadores foram os serviços e a indústria, confirmando a perspectiva de Antunes (1995) e Rifkin (1995) sobre a reconfiguração do mercado de trabalho.

Portanto, não se pode mais imaginar que alguém se torna catador por não ter experiência em ramo algum, na verdade o fator que mais influenciou os catadores entrevistados a trabalhar nesta atividade foi o desemprego, com 57\% das respostas, sendo que $14 \%$ foram indicados por alguém que já trabalhava como catador. Para $10 \%$ houve atração pela boa remuneração, outros $10 \%$ pela independência e $10 \%$ dizem que sempre trabalharam com lixo e apenas continuam.

Gráfico 1: Atividades exercidas antes de se tornar catador 

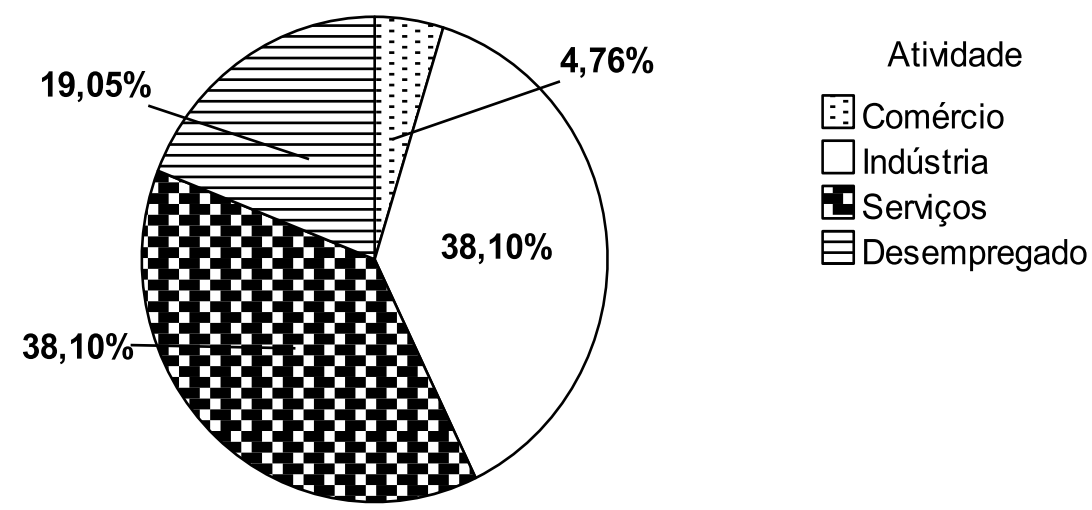

Fonte: Dados da pesquisa (2007)

Ademais, segundo os dados coletados, apenas $24 \%$ dos entrevistados são analfabetos, enquanto que $52 \%$ possuem o $1^{\circ}$ grau completo e $24 \%$ tem o $2^{\circ}$ grau completo. Aliás, um dos entrevistados chegou a começar um curso superior, porém não completou por falta de recursos financeiros, o que demonstra que a maioria das pessoas pesquisadas e que atuam nesta atividade tem escolaridade considerada alta, mas simplesmente não tem outra opção, diminuindo desta forma a importância deste personagem no contexto social. Novamente temos a questão da exclusão do mercado de trabalho e da mudança do perfil original desta atividade, ou seja, como afirma SoaresBaptista (2003) os catadores funcionam como uma disfunção tanto com relação a coleta de resíduos como também a organização da capacidade das empresas conseguirem incluir os trabalhadores no processo produtivo.

Ainda assim, ao se indagar a idade dos entrevistados percebeu-se que: $10 \%$ têm entre 10 e 25 anos, $38 \%$ têm entre 41 e 55 anos, sendo que a maioria, ou seja, $43 \%$ ficam na faixa dos 26 aos 40 anos, e nenhum dos entrevistados tem acima de 65 anos, o que pode ser explicado pelo fato da atividade exigir grande esforço físico e resistência para ser realizada. Aliás, com relação a tal exigência há uma forte tendência a encontrar mais homens nesta atividade, o que foi confirmado pela pesquisa, visto que $71 \%$ dos entrevistados são do sexo masculino e apenas $29 \%$ são mulheres, por vezes, as próprias esposas. De qualquer forma, tal informação deixa claro também que este tipo de trabalho não é uma opção de quem está na fase da aposentadoria, pelo contrário, são pessoas capacitadas e com potencial para representarem de forma perfeita a população economicamente ativa do país.

Quanto à origem, referindo-se ao local de nascimento, constatou-se que 67\% nasceram em Lages, $19 \%$ nasceram em São Joaquim, 10\% nasceram em Urubici e os 5\% restantes nasceram em outras cidades da região da Amures, ou seja, não são pessoas que se motivaram a ir para a região explorar este tipo de atividade, mas sim pessoas que ali se encontravam e viram neste uma oportunidade de trabalho. Portanto, está claro que não há nenhum estímulo por parte das organizações que levam as pessoas a adotar esta alternativa.

De qualquer forma, ao mesclar as informações um dado mostra-se bastante importante, pois se trata de pessoas "nativas", por assim dizer, com grau de escolaridade alto e em sua maioria homens desempregados com idade média de 33 anos que fizeram esta opção por não ter alternativa, o que justifica a preocupação em abordar o aspecto remuneração a seguir.

\subsection{Remuneração da atividade dos catadores}

Com relação à renda, a pesquisa apurou que, $24 \%$ dos entrevistados obtinham menos de um salário mínimo em suas atividades anteriores, $67 \%$ entre um e dois salários mínimos, sendo que nenhum deles afirmou receber entre três e cinco salários mínimos e $10 \%$ afirmaram que ganhavam acima de cinco salários mínimos. Portanto, $77 \%$ deles tinham uma renda acima de um salário mínimo com suas atividades anteriores o que poderia ser um motivo para não mudar de ramo. 
Gráfico 2: Comparação entre renda anterior e renda atual dos catadores.
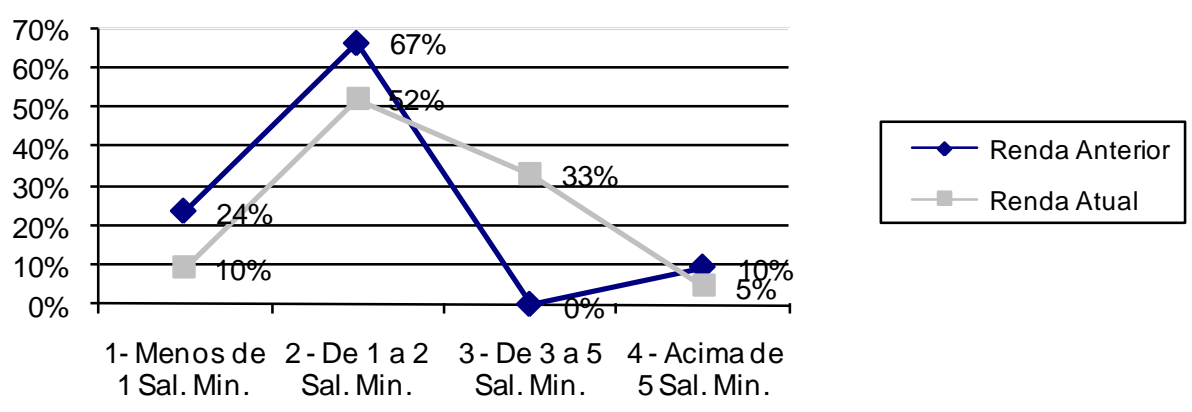

Fonte: Dados da pesquisa (2007).

Todavia, quando questionados sobre a renda atual, $10 \%$ disseram que ganham até um salário mínimo, $52 \%$ disseram que ganham atualmente entre um e dois, outros 33\% disseram ganhar entre três e cinco e 5\% afirmaram ganhar acima de cinco salários mínimos. Em suma, atualmente, $90 \%$ estão na faixa de renda acima de um salário e apenas $10 \%$ ganha menos de um salário mínimo como catador de lixo, o que explica o resultado referente à relação trabalho e renda, a qual apenas $5 \%$ dos entrevistados acreditam ser péssima. Para $10 \%$ esta relação é muito ruim, para $29 \%$ é ruim e $57 \%$ acham que é boa a relação entre trabalho e renda nesta atividade, principalmente se comparada a outras atividades que eles já desenvolveram anteriormente. Cabe comentar que a soma do resultado das opções consideradas ruins chega a $44 \%$, enquanto que $57 \%$ do total consideram que a atividade tem um bom custo e gera o benefício da renda.

Entretanto, esta é certamente uma forma equivocada de explorar os dados, pois poderia levar a conclusão de que trabalhar na cadeia de reciclagem do lixo aumenta a renda, como pode ser visto no Gráfico 3. Diz-se de forma equivocada, pois não se pode esquecer que para trabalhar como catador estas pessoas contam com a ajuda dos filhos ou esposa/marido, representados por 14,29\% cada; de familiares em 19,05\% e amigos em 33,33\%. Enquanto, somente 19,05\% trabalham sozinhos (gráfico 3); logo, apesar de acreditarem estar ganhando mais a comparação absoluta que fazem desconsidera aspectos fundamentais que explicam o aumento da renda, como, por exemplo, o fato de contarem com a ajuda de outras pessoas para alcançar tal resultado o que certamente não acontecia em seus empregos anteriores.

Aliás, a explicação para tal influência é simples, pois com a ajuda de outras pessoas é possível pulverizar sua atuação, ou seja, cada um segue um caminho distinto e marcam um ponto de encontro para juntar o material recolhido. Assim, estas equipes de trabalho conseguem um volume maior de material para reciclagem, o que gera uma renda também maior e reforça a idéia de que aumento de renda definitivamente não é um estímulo para tal atividade.

Gráfico 3: Catadores que trabalham em equipe 


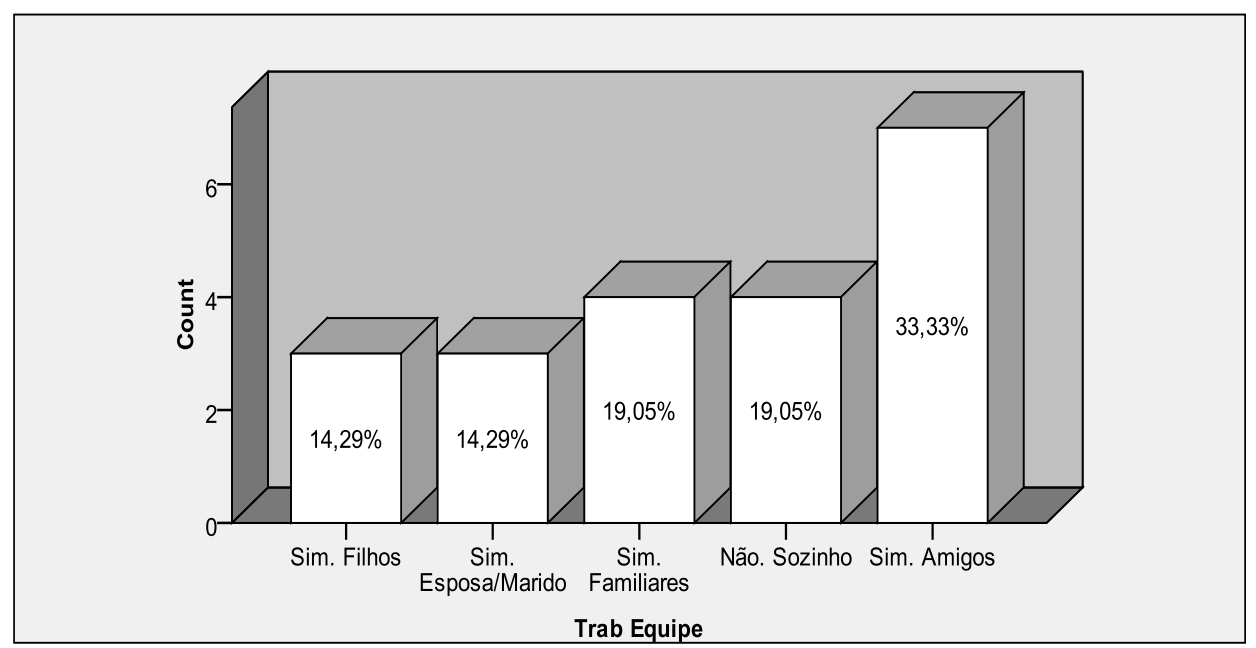

Fonte: Dados da Pesquisa (2007)

Ainda assim, para evidenciar o que foi dito, separou-se na amostra os quatro catadores que afirmaram trabalharem sozinhos e comparou-se a renda atual com a anterior, conforme o gráfico 4. Neste caso pode-se perceber que enquanto dois catadores aumentaram a renda ao decidir trabalhar com reciclagem, os outros dois mantiveram suas respectivas rendas constantes. Portanto, com essa comparação feita em igualdade de condições, se torna evidente que não é possível afirmar que a reciclagem oferece de fato um atrativo relacionado à renda.

Com relação ao tempo de serviço levantou-se junto aos entrevistados o tempo em que estão desempenhando esta atividade, ao passo que $10 \%$ afirmaram desenvolver a função há menos de seis meses, outros $10 \%$ de seis meses a um ano, sendo que a maioria, ou seja, 57\%, afirma trabalhar como catador no período de um a cinco anos e os $24 \%$ restantes atuam nesta atividade a mais de cinco anos, portanto, não se trata mais de uma atividade transitória como indicavam os estudos de Carmo, Oliveira e Migueles (2004), mas de uma nova configuração como apresentada por (MARCHI, 2006).

Gráfico 4: Relação entre a rendas atual e anterior dos catadores que trabalham sozinhos

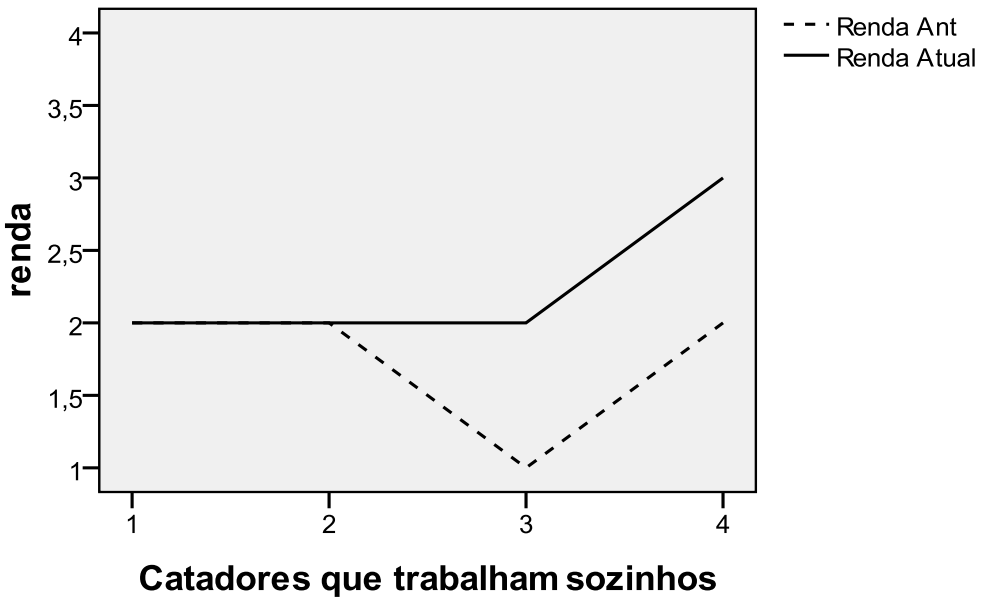

Fonte: Dados da Pesquisa (2007)

Uma análise apressada dos dados poderia sugerir que se trata de uma ocupação onde a renda aumenta ao longo do tempo, porém, ao fazer uso do boxplot no gráfico 5, com uma maior precisão da assimetria da distribuição de valores, evitando que o conjunto de valores seja afetado por valores extremos, foi possível notar que conquista-se uma renda maior em pouco tempo, porém, esta renda 
pode se manter fixa. De forma mais precisa tem-se que o tempo de atividade "1" representa até 6 meses, "2" de 6 meses a 1 ano, "3" de 1 ano a 5 e "4" acima de 5 anos.

Neste caso, ao mesmo tempo em que a média das pessoas atingem de 1 a 3 salários mínimos no período que compreende 1 a 5 ano, 50\% desta amostra se mantém neste patamar mesmo após 5 anos. Sendo assim, uma visão imediatista poderia levar algumas pessoas a ingressarem em tal atividade e não enxergarem que poderão estar estagnados em pouco tempo, aliás, muito pouco tempo, até porque o trabalho é pesado e a cada ano suas condições físicas ficam mais prejudicadas; porém, não é o que acontece.

Gráfico 5: Relação entre a renda dos catadores e o tempo de serviço

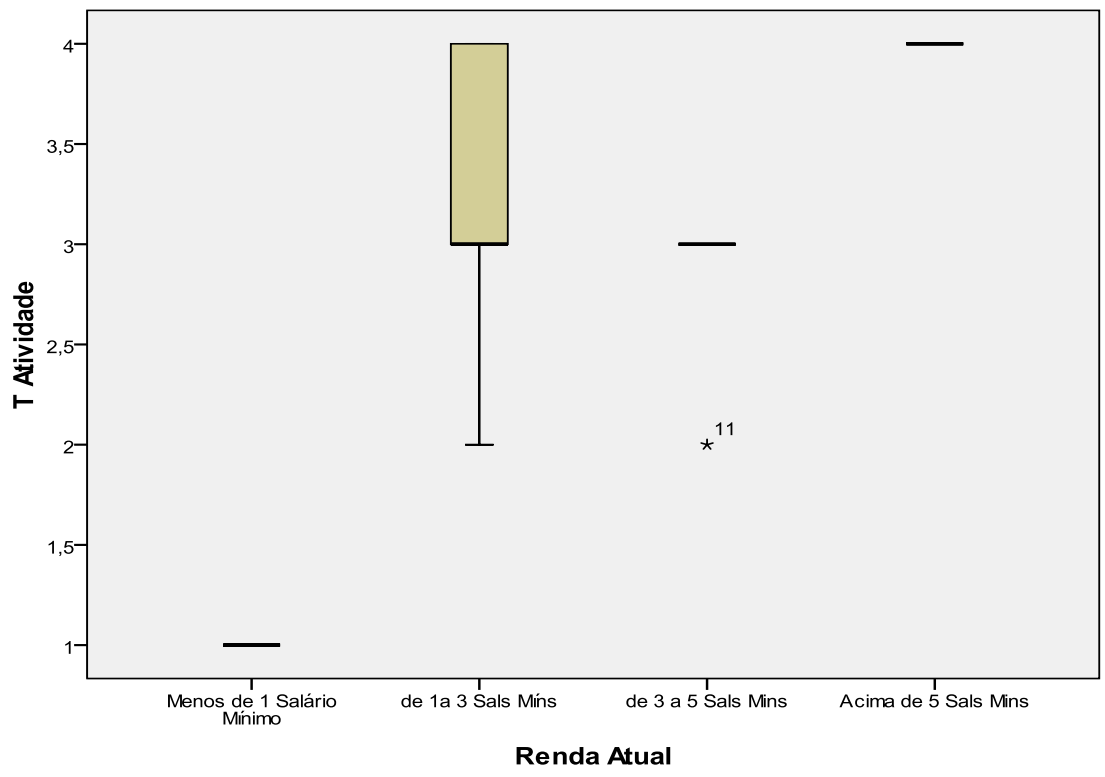

Fonte: Dados da Pesquisa (2007)

Somada a estas questões, foi constatado que em $100 \%$ dos casos as pessoas trabalham por conta própria afirmando que é melhor do que trabalhar como cooperado, visto que conseguem controlar melhor os seus ganhos, seu horário e principalmente, porque nas cooperativas tem muita política, desorganização e desentendimentos, visão esta que possuem do sistema cooperativista e justifica o fato da cooperativa de catadores da cidade ter sido extinta há alguns anos. Esses dados reafirmam aqueles citados por Carmo (2005) referindo-se a um estudo de Putnam (2002) sobre as dificuldades desses atores constituírem um capital social.

Em outras palavras, como principais vantagens os catadores citaram: não ter patrão (19\%); fazer seu próprio horário (24\%); é melhor que outras atividades (29\%); as pessoas ajudam (19\%); e boa remuneração (5\%). Assim, $48 \%$ dos entrevistados dizem não ver problemas nesta atividade inferindo que a mesma tem mais prós do que contras para os catadores. Contudo, desta forma tais profissionais se tornam ainda mais vulneráveis ao sistema, trabalhando em $52 \%$ dos casos sem seguir padrão algum, afirmando que cada dia é de um jeito, enquanto $48 \%$ dizem ter um padrão de trabalho definido, visto que realizam tarefas diárias sistematicamente, como coletar o lixo sempre nos mesmos lugares, organizar o lixo, entre outros. Portanto, o segundo grupo desenvolveu uma metodologia para tornar a coleta de resíduos mais eficiente, corraborando com a afirmação de Carmo (2005) que afirma que esses trabalhadores desenvolvem um expertise que lhe proporciona uma vantagem com relação a outros atores da cadeia.

Para complementar essas informações, no que se refere à fonte de coleta de lixo, ficou evidenciado que $61 \%$ coletam lixo em todos os lugares sem distinção, $9 \%$ coletam nas residências, outros $9 \%$ coletam no comércio, sendo que $22 \%$ coletam diretamente da rua. Curiosamente, nenhum entrevistado afirma coletar lixo nas indústrias pelo fato de ser muito afastado da cidade e 
por ter um volume muito grande de lixo que já é repassado diretamente aos que possuem maior capacidade de transportar todo o material. Esse aspecto corrobora com o trabalho desenvolvido por Cardoso e Carvalho Neto (2004), demonstrando a relevância da cooperativa para a organização do trabalho dos catadores e também de Soares-Baptista (2003) que identifica uma segregação do catador individual colocando abaixo da cadeia produtiva.

Neste momento vale ressaltar uma relação que corrobora diretamente com a posição deste trabalho, pois apesar dos entrevistados afirmarem que o volume de lixo coletado é de: em $24 \%$ dos casos, 100 a $500 \mathrm{~kg}$ ao mês; $48 \%$ de 500 a $1000 \mathrm{~kg}$; outros $24 \%$ de $1000 \mathrm{~kg}$ a $5000 \mathrm{~kg}$; e $5 \%$ coletam acima de $5000 \mathrm{~kg}$ de lixo ao mês, volume que pode ser considerado elevado e explicado pelo trabalho em equipe, ao relacionar tal volume com a renda atual, utilizando a análise fatorial pelo sistema kaiser (Tabela 1), verifica-se que a correlação entre as variáveis não é uma boa idéia, pois se mostra má, com apenas 0,5 KMO. Ademais o sig. é diferente de 0 ; logo, não há correlação entre as variáveis, provando que a pessoa pode trabalhar mais e não ganhar mais por isso.

Tabela 1: Teste Kaiser de relação entre renda atual e volume de lixo coletado

\begin{tabular}{|l|l|r|}
\hline \multicolumn{2}{|c|}{ KMO and Bartlett's Test } \\
\hline Kaiser-Meyer-Olkin Measure of Sampling Adequacy. &, 500 \\
\hline Bartlett's Test of Sphericity & Approx. Chi-Square & 1,451 \\
\cline { 2 - 3 } & DF &, 228 \\
\cline { 2 - 3 } & Sig. & \\
\hline
\end{tabular}

Fonte: Dados da Pesquisa (2007)

Assim, ainda que a contribuição desses trabalhadores seja fundamental para aumentar os índices de reciclagem, como afirma o CEMPRE (2005), e minimizar os dados sociais e ambientais da questão dos resíduos sólidos, a retribuição que lhes é dada no que diz respeito a dignidade do trabalho está aquém daquilo que eles oferecem à sociedade.

\subsection{Relação com a sociedade}

Ao serem questionados se esta atividade é valorizada pela sociedade, $43 \%$ dos entrevistados afirmam que sim, porque as pessoas reconhecem que seu trabalho ajuda a limpar o meio ambiente e os auxiliam guardando e organizando o lixo. Por outro lado, para 57\% a atividade não é valorizada, pois, na concepção deles, as pessoas associam este trabalho a pessoas sujas, existe muito preconceito, muito deboche e até se sentem humilhados em algumas situações. Na verdade, não são poucas as vezes que as pessoas confundem os catadores com mendigos, o que de fato não condiz com a realidade.

Essa identificação equivocada está vinculada as origens da atividade que, como afirma BRACELPA (2007), inicialmente estava vinculada a moradores de rua e a partir da década de 60, com o acirramento do mercado de trabalho incluiu nesse cenário trabalhadores excluídos do mercado de trabalho.

Outro aspecto interessante da pesquisa foi a questão que tratou do perigo envolvido pela atividade de catador, onde $48 \%$ dos entrevistados afirmam que não há qualquer perigo neste trabalho, desde que o catador tome os cuidados necessários, mas outros 52\% acreditam que há muitos perigos como: se cortar com vidros, alumínio, ou outros materiais, pegar doenças, ser roubado, ser atropelado por trabalhar na rua e ser atacado por animais. Essa questão também foi identificada por Soares-Baptista (2003) que constatou em seus estudos a vulnerabilidade desses trabalhadores com relação a sua segurança pessoal.

Portanto, apesar da escolaridade alta dos catadores e de todos consideram grande a contribuição desta atividade para o meio ambiente, devido ao fato desta evitar a poluição dos rios, a utilização e destruição dos recursos naturais e da ecologia, poucos têm consciência do perigo que correm e ao optar por trabalhar por conta própria não se informam sobre os riscos e muito menos se 
previnem. Neste sentido, as cooperativas certamente ajudariam a reverter este quadro com palestras de conscientização e fornecendo equipamentos de segurança e até mesmo uniformes que fariam com que tais profissionais recebessem um pouco de dignidade e não fosse apenas referência na reciclagem, mas sim uma questão social, como sugere o título deste trabalho.

As justificativas dessa dificuldade organizativa foram abordadas por Carmo, Oliveira e Migueles (2004) que identificaram as dificuldades desses sujeitos em constituírem sua auto-estima a partir de um conceito de degradação como o "lixo", nesse sentido se as cooperativas, por um lado, representam uma forma organizativa capaz de melhorar suas condições de trabalho, por outro sedimentariam um processo de identificação com uma atividade que não é acolhida de forma positiva pela sociedade expondo esses trabalhadores a um processo de contradição permanente entre melhorar suas condições de vida e ao mesmo tempo sedimentarem uma identidade não desejada.

\subsection{Relação com as empresas}

No que diz respeito à relação da atividade de catador com as empresas, buscou-se observar qual a participação das empresas no aspecto de segurança que o catador possui para desenvolver esta atividade. Verifica-se que todos os participantes da pesquisa afirmam que nem as empresas que entregam o lixo nem aquelas que recolhem dão nenhum tipo de apoio ao catador, seja ele financeiro, de treinamento ou equipamento de proteção. No entanto, chega a ser curioso que tais profissionais eximam as organizações de qualquer culpa, tanto que cerca de $72 \%$ consideram que elas tem pequena ou nenhuma responsabilidade com o lixo produzido, como pode ser verificado no Gráfico 6. O que demonstra uma certa ingenuidade por parte dos catadores nesta relação.

Como foi dito por Carmo, Oliveira e Migueles (2004) as empresas não se relacionam com esse tipo de trabalhador, visto que o volume de resíduos que elas disponibilizam direciona esse produto para outros elos da hierarquia dos catadores como cooperativas.

Inclusive, ao indagar os catadores sobre o que as empresas podem fazer para melhorar a segurança e a remuneração da atividade, $48 \%$ dos entrevistados afirmaram que poderiam dar equipamentos de proteção, $10 \%$ disponibilizar alojamento para os catadores, $24 \%$ consideram que seria importante que as empresas organizassem o lixo para a coleta e $19 \%$ não souberam dizer em que as empresas poderiam ajudar. Demonstrando que não é falta de informação, mas sim por equivocadamente acreditarem que são eles próprios os maiores responsáveis pelo destino do lixo produzido, podendo as empresas ou as prefeituras simplesmente colaborar dando sacos com cores diferentes para que as pessoas pudessem separar seu lixo, identificando o destinado à reciclagem, não sendo sua obrigação fazê-lo.

Vale salientar que, a relação entre esses trabalhadores e o setor público ainda é uma questão em discussão, se em um primeiro momento ela chegou a ser conflitiva, atualmente ela é a demonstração da incapacidade do poder público em lidar adequadamente com essa questão (SOARES-BAPTISTA, 2003).

Gráfico 6: Responsabilidade das empresas com o lixo produzido 


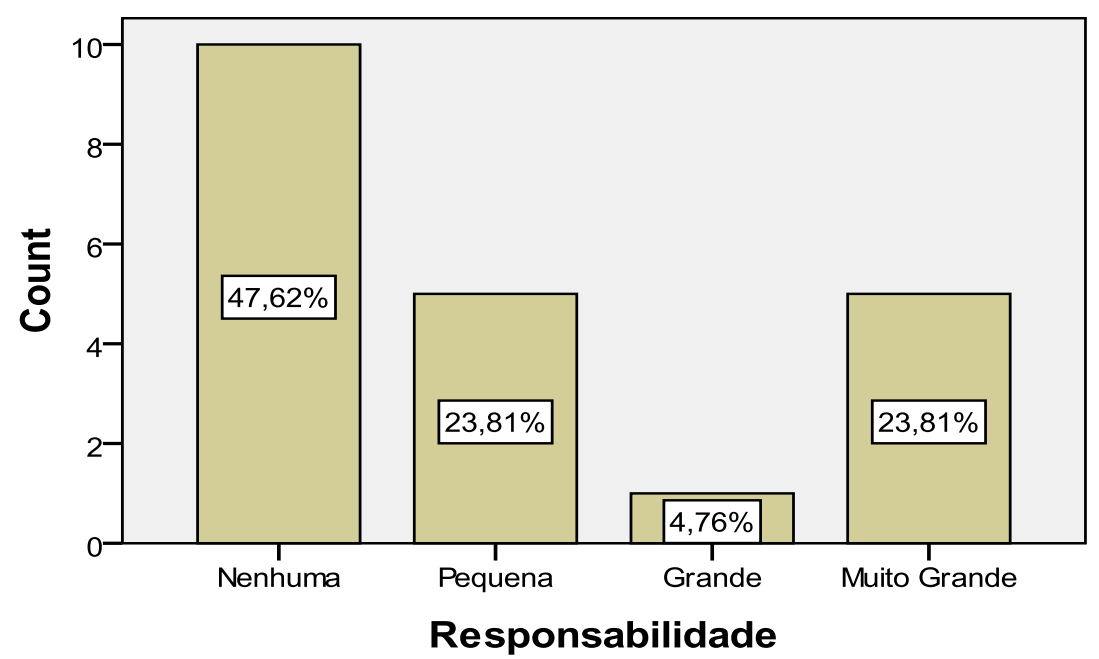

Fonte: Dados da pesquisa (2007).

Em suma, os principais problemas apontados pelos catadores foram: falta apoio das empresas, entidades e governos para a atividade (14\%); falta reconhecimento da sociedade (5\%); falta segurança para a atividade (5\%), que não é organizada e pode ser vista como um movimento "pirata", ou uma disfunção; e, por fim, 10\% afirmam que ganham pouco.

Quando questionados se pretendem continuar nesta atividade, enquanto que $52 \%$ dos entrevistados disseram que sim porque melhoraram de vida, hoje ganham mais e pretendem crescer na atividade, comprar equipamentos; $48 \%$ afirmam que não pretendem continuar, visto que pioraram as condições de trabalho e que, ao surgir uma oportunidade de emprego, pretendem mudar confirmando a afirmação de Carmo, Oliveira e Migueles (2004) sobre a transitoriedade que pretendem para essa atividade.

Aliás, no aspecto que tratou do futuro desta atividade, $57 \%$ dos entrevistados acreditam que o cenário irá melhorar principalmente as condições de trabalho e a conscientização da sociedade e empresas para o papel dos catadores de lixo, e, com isso, acreditam que a remuneração irá aumentar. Contudo, $43 \%$ acham que as condições para desenvolver esta atividade vão piorar no futuro, visto que já tem muita gente catando lixo e a tendência é aumentar ainda mais a concorrência, principalmente pelo elevado índice de desemprego no país, essa questão da concorrência que esse mercado tem gerado foi tratada por Carmo (2005) que abordou sobre a hierarquia no processo de catação e a questão do desemprego nessa atividade.

Como dado complementar, foi possível observar na pesquisa que a cooperativa foi extinta e em seu lugar foi criada uma rede informal de coleta e organização do lixo, feita basicamente pelos catadores e pelos intermediários (além de coletar armazenam). Estes últimos se caracterizam por terem maiores condições financeiras e de estrutura, visto que possuem caminhões, máquinas e equipamentos para prensar o lixo, empacotar e enfardar, organizando a remessa novamente para as fábricas que se situam no início da cadeia de valor desta atividade. Ainda assim, tais profissionais não recebem nenhum tipo de estímulo em sua atividade.

Resumidamente, pode-se dizer que a falta de apoio tanto das organizações quanto da sociedade faz com que as pessoas busquem tal atividade na maioria das vezes por falta de opção. Provando que para ser catador é preciso se dedicar à profissão mais do que tudo, pois os riscos são inúmeros e o reconhecimento praticamente nulo. Sem contar que é uma atividade que exige muito da pessoa tendo um tempo de vida útil bastante curto. Contudo, mesmo sendo extremamente alta a importância deste personagem na teia produtiva em que atua, a pesquisa mostra que da maneira como se está estruturado será necessário chegar ao caos para tratar esta como uma questão social.

\section{CONSIDERAÇÕES FINAIS}


O objetivo deste artigo foi analisar a situação social dos catadores de lixo, no sentido de perceber como eles se inserem na dubiedade da dimensão ambiental, pois ao mesmo tempo em que o lixo lhes proporciona trabalho informal, por outro as condições de vida e salubridade nem sempre correspondem à dignidade social.

Ao mesmo tempo procura estabelecer os nexos desses atores com as empresas que se constituem na principal fonte de produção de resíduos dada a natureza da produção industrial não possuir características de sustentabilidade como ocorre na natureza, conforme citado por Capra (1996).

Como visto, esse processo gera uma dubiedade, pois de um lado ameniza os processos de exclusão social de pessoas que não encontram outras formas de sobrevivência consideradas pelos entrevistados como melhores que a anterior; mas de outro mascara a ineficiência do sistema produtivo que não é capaz de lidar com o ciclo que relaciona natureza - matéria-prima - produto consumo - descarte, essa última etapa não retorna para o processo produtivo nem para o sistema natural, constituindo-se em uma questão ambiental de dimensões avassaladoras.

O desenvolvimento social e a qualidade de vida como objetivos tomados como finalidades mais amplas da sociedade têm repercussões profundas, na medida em que o social deixa de ser apenas um setor para se tornar uma dimensão de todas as nossas atividades (meio rural, ambiental, comercial, etc). Não se trata de optar pelo interesse econômico ou social, e sim articulá-los. Essa articulação deve ser incorporada à gestão de políticas, ações e programas e é nesse contexto que a questão dos resíduos deve ser inserida.

Pensar formas mais equilibradas no relacionamento entre os atores envolvidos nesse processo envolve uma concepção de gestão complexa, uma vez que não está vinculada unicamente a processos produtivos industriais ou empresas privadas, mas nas inter-relações entre a dimensão pública e privada e destas com o movimento da sociedade, portanto, com uma preocupação com o todo social.

A pesquisa mostrou que existe um grande distanciamento da ação dos catadores (elo inicial da cadeia) com as organizações. Tal cenário dificulta a construção de redes, como proposto por Cardoso e Carvalho Neto (2004) que consideram que somente o encurtamento dessa cadeia poderia envolver as empresas em ações mais efetivas no que diz respeito a redução da produção de rejeitos. $\mathrm{O}$ que significa aproximar mais esses dois elos para que ao dialogarem possam contribuir com ações sociais e ambientais.

O cenário atual exime as organizações dessa responsabilidade e transferem para a sociedade e para o setor público a tarefa da destinação dos resíduos, e nesse contexto o catador se constitui como no agente que inicia esse processo produzindo imagens e significados contraditórios: aquele que contribui para redução do problema ambiental, o excluído que dadas as condições sociais e econômicas necessita do lixo como fonte de sobrevivência, um novo profissional que torna o rejeito em atividade lucrativa.

Agravando esse cenário surgem novos atores visto que atualmente, muitas pessoas que já possuem uma renda estão recolhendo lixo reciclável em ambientes, como o de trabalho ou nos que possui algum tipo de relação e estão vendendo para obter um acréscimo na renda. Esse aspecto demonstra que a quantidade de material disponível para os catadores pesquisados tende a reduzir cada vez mais e, portanto suas condições de trabalho tendem a deteriorar-se ainda mais, pois lhes restarão o lixo do lixo.

Outras imagens poderiam ser criadas para ilustrar a questão, contudo, o que interessa perceber é que o atual sistema legitima e não questiona a produção de rejeitos e a responsabilidade daqueles que os produzem, ou seja, as organizações.

A justificativa dessa questão é que o consumo é de interesse social e a produção de rejeitos e resíduos é absorvida pela sociedade através da criação de uma cadeia produtiva do lixo que proporciona a geração de emprego e renda.

Contudo, dada as condições históricas que geraram tal panorama esse percurso talvez seja necessário para gerar um capital social que, em longo prazo, seja capaz de incentivar as empresas 
privadas envolvidas a repensar sua lógica de produção no que diz respeito a suas ações residuais.

Trata-se da construção de uma nova forma de relacionar a dimensão econômica da social.

\section{REFERÊNCIAS}

ABREU, M. de F.. Do lixo à cidadania: estratégias para a ação. $1^{\text {a }}$ Edição. Fórum Nacional Lixo e cidadania: Unicef e Caixa Econômica Federal, 2001.

ANDRADE, R. O. B.; TACHIZAWA, T.; CARVALHO, A. B.. Gestão ambiental. São Paulo: Ed. Makron Books, 2004.

ANTUNES, R. Adeus ao Trabalho? Ensaios sobre as metamorfoses e a centralidade do mundo do trabalho. $2^{\text {a }}$ edição. São Paulo, Cortez, 1995.

ASSOCIAÇÃO BRASILEIRA E CELULOSE E PAPEL. BRACELPA. Disponível em <www.bracelpa.org.br/ - 8k> . Acesso em 20 de maio de 2007.

CAPRA, F. A teia da vida: uma nova compreensão científica dos sistemas vivos. São Paulo: Cultrix, 1996.

CARDOSO, M. B. R., CARVALHO NETO, A. Gerando renda e construindo capital social a partir da coleta de lixo: o sucesso de uma parceria entre o Terceiro Setor, empresas socialmente responsáveis e o poder local. In: ENAPG, 2004. Rio de Janeiro, Anais... 2004.

CARMO, M. S. do, OliveIRA, J. A. P. de, MIGUELES, C. P. Significado do Lixo e Ação Econômica - a Semântica do Lixo e o Trabalho dos Catadores do Rio de Janeiro. In: ENANPAD, 2004, Curitiba, Anais..., 2004.

CARMO, M. S. do. A Semântica 'Negativa' do Lixo como Fator 'Positivo' à Sobrevivência da Catação - Estudo de Caso sobre a Associação dos Recicladores do Rio de Janeiro. In: ENANPAD, 2005, Brasília, Anais..., 2005.

CASE, T.J. An Illustrated Guide to Theorical Ecology. Oxford University Press. New York, 2000.

CEMPRE. Dúvidas. Disponível em: 〈http://www.cempre.org.br >. Acesso em 10 de dezembro 2005.

DE MASI, D. O ócio criativo. Rio de Janeiro: Ed. Sextante, 2000.

DOWBOR, L. A gestão social em busca de paradigmas. In: RICO, E.M e RAICHELIS, R. (org)

Gestão Social: uma questão em debate. São Paulo, SP: EDUC, 1999.

FERRARA, L. D’A. Os significados urbanos. São Paulo: Perspectiva, 2000.

INSTITUTO BRASILEIRO DE GEOGRAFIA E ESTATÍSTICA - IBGE. Disponível em <http://www.ibge.gov.br/> Acesso em 21de fevereiro de 2007.

JACOBI, P. Movimentos reivindicatórios urbanos e Estado no Brasil. Canadian Journal of LatinAmerican and Caribbean Studies. Montréal, v. 16, n.31, 1991. 
KORTEN, D. Getting to the 21st Century: Voluntary Action and the Global Agenda. West Hartford: Kumarian Press, 1990.

MAGERA, M.C. Os Empresários do Lixo - um Paradoxo da Modernidade: análise interdisciplinar das cooperativas de reciclagem de lixo. Campinas, Editora Átomo, 2003.

MARCHI, C. M. D. F.. Gestão de Resíduos Sólidos: um Caso nos Pequenos e Médios Municípios Baianos. In: ENANPAD, 2006, Salvador, Anais..., 2006.

MORAIS, J. F. R. de. Filosofia da Ciência e da Tecnologia. 2. ed. Campinas-SP: Ed. Papirus, 1997.

MORIN, E.; KERN, A. B.. Terra Pátria. São Paulo: Ed. Sulina, 2000.

PERIN, A. Geração de renda a partir de resíduos recicláveis: análise de duas associações de Florianópolis. Dissertação de Mestrado, Florianópolis, Universidade Federal de Santa Catarina, 2003.

PUTNAM, R. D. Comunidade e Democracia: a experiência da Itália moderna. 3.ed. Rio de Janeiro: FGV, 2002.

RIFKIN, J. O fim dos empregos: declínio inevitável dos níveis dos empregos e a redução da força global de trabalho. São Paulo: Makron Books, 1995.

SENGE, P. A Quinta Disciplina. São Paulo: Editora Nova Cultura, 2002.

SOARES-BAPTISTA, Rozalia Del Gáudio. Reciclagem, Ação Social e Política de Gerenciamento do Lixo em São Paulo. In: ENANPAD, 2003, Atibaia, Anais..., 2003.

Data do recebimento do artigo: 13/10/2010

Data do aceite de publicação: 29/11/2011

Revista de Gestão Social e Ambiental - RGSA, São Paulo, v. 5, n. 3, p. 17-35, set./dez. 2011. 